Ю. Н. Молдованова, Е. Б. Тарбагаева

Красноярск, Россия

\title{
«ПРЕВЕНТИВНОЕ ПРАВОСУДИЕ» - ЛИНГВИСТИЧЕСКИЙ АСПЕКТ
}

Статья представляет лингвистическое обоснование в защиту использования вызвавшего в юридическом сообществе полемику термина «превентивное правосудие» применительно $к$ институту нотариата. Аргументируется вывод о том, что словосочетание «превентивное правосудие» является узкоспециальным научным термином и нарушение его смысловой изелостности, происходящее при формальном подходе к анализу, ведет к утрате его значения.

Ключевые слова: превентивное правосудие, нотариат, терминоведение, терминосистема, языковая единица.

Сведения об авторе: Юлия Николаевна Молдованова, магистрант юридического института Сибирского федерального университета. 660048, Красноярск, ул. Маерчака, 6. E-mail: Yuliyamoldovanova@yandex.ru.

Сведения об авторе: Елена Борисовна Тарбагаева, кандидат юридических наук, дочент кафедры гражданского проиесса юридического института Сибирского федерального университета. 660048, Красноярск, ул. Маерчака, 6. E-mail: civil.law.process@gmail.com.

Y. N. Moldovanova, E. B. Tarbagaeva

Krasnoyarsk, Russia

\section{PREVENTIVE JUSTICE - LINGUISTIC ASPECT}

This article represents linguistic analysis of the term "preventive justice» in the sphere of notarial profession. The aim is to support the idea that collocation «preventive justice» is a niche scientific term and formal approach to its analysis leads to distortion of its meaning thus causing loss of sense.

Key words: Preventive justice, notarial profession, terminology studies, system of terms, language unit.

About the author: Yuliya Nikolaevna Moldovanova, postgraduate at the Chair of Civil Procedure, Law Institute, Siberian Federal University. ul. Maerchaka, d.6, Krasnoyarsk, 660048. Email:yuliyamoldovanova@yandex.ru. 
About the author: Elena Borisovna Tarbagaeva, Candidate of Juridical Sciences, Associate Professor at the Chair of Civil Procedure, Law Institute, Siberian Federal University. ul. Maerchaka, d.6, Krasnoyarsk, 660048. E-mail: civil.law.process@gmail.com.

Статья 1 Основ законодательства Российской Федерации о нотариате (далее Основ) определяет, что нотариат призван обеспечивать защиту прав и законных интересов граждан и юридических лиц путем совершения нотариусами предусмотренных законодательными актами нотариальных действий от имени Российской Федерации, а также указывает на других лиц, имеющих право на совершение нотариальных действий. Законодательно понятие нотариата не раскрывается, акцентируется общая задача нотариальной деятельности - защита прав и законных интересов посредством совершения нотариальных действий и выполнение нотариусом публичной функции от имени государства. Решение проблемы определения понятия нотариата и его правовой природы доктринально решается поразному.

В целом в литературе принято говорить о нескольких основных значениях термина нотариат: «во-первых <..> систему органов и должностных лиц, включающую нотариусов и иных лиц, наделенных в соответствии с законом правом совершения нотариальных действий; вовторых, отрасль законодательства, нормами которой регулируется нотариальная деятельность; в-третьих, учебный курс, предметом которого является изучение вопросов нотариального производства и деятельности его участников» [Ярков 2003: 1].

В доктрине выработано множество определений, отражающих представления о данном правовом институте, высказываются различные точки зрения относительно понятия нотариата, однако единого мнения о природе нотариата так и не выработано. В литературе отмечается, что нотариат - понятие многозначное, его можно рассматривать в различных аспектах [Тарбагаева 2006: 9]. Нотариат также принято соотносить с понятием превентивного правосудия [Жуйков 1998: 13]. 
В отечественной доктрине концепция превентивного правосудия применительно к институту нотариата является дискуссионной по нескольким причинам, в частности, если превентивная (предупредительная) функция нотариата не оспаривается, вызывает возражения использование применительно к данной сфере термина «правосудие», который понимается юристами как «форма государственной деятельности, которая заключается в рассмотрении и разрешении судом отнесенных к его компетенции дел» [Додонов 1998: 250]. Логика такого рода рассуждений основана на том, что, согласно ст. 118 Конституции РФ, правосудие в Российской Федерации осуществляется только судом посредством конституционного, гражданского, административного и уголовного судопроизводства. Такой подход является результатом логического анализа термина «превентивное правосудие», который заключается в разложении словосочетания на части и оценки возможности применения каждого из них к нотариату. Но такой подход не оправдан, так как не учитывает статуса данного понятия как термина, который нельзя расчленять, так как он является неделимым единством.

Кроме того, несмотря на указание в статье 1 Основ на то, что нотариат призван обеспечивать защиту прав и законных интересов граждан и юридических лиц, стоит признать, что защита права может осуществляться только там, где произошло нарушение права, либо право оспаривается, а предметом нотариального производства становятся по общему правилу гражданские дела бесспорного характера. Защита права осуществляется только таким нотариальным действием, как совершение исполнительной надписи. Поэтому отнесение деятельности нотариата к защите права в целом не совсем оправданно. Кроме того, это связано, вероятно, также со смешением понятий «охрана прав» и «защита прав», присутствующих в отечественном законодательстве.

Превентивное правосудие ассоциируется с нотариатом латинского типа. Термин «превентивное правосудие» возник в 1998 году и является результатом терминотворчества Виктора Мартениановича Жуйкова, 
профессора кафедры гражданского процесса юридического факультета МГУ им. М. В. Ломоносова.

Сам автор так говорит о термине: «Какое содержание мы вкладываем в понимание нотариата как института превентивного, предупредительного правосудия? Прежде всего, это те случаи, когда нотариус непосредственно обеспечивает защиту прав гражданина, чем предупреждает необходимость обращаться к судье за защитой тех прав. В других случаях, когда все же не удается предотвратить обращение к правосудию, нотариальные действия максимально облегчают и упрощают деятельность правосудия. Если наш свободный российский нотариат латинского типа в состоянии выполнить эти задачи, то он может рассматриваться в качестве института превентивного, предупредительного правосудия» [Жуйков 1998: 13].

Следует принимать во внимание, что «для наук, имеющих в качестве объектов знаковые, языковые системы, важное значение имеет различение языка (языка первой ступени) и метаязыка (языка второй ступени). К таким наукам относится и юриспруденция. Неразличение двух аспектов (уровней) языка в юридической науке и практике приводит к возникновению необоснованных коллизий, споров... Таким образом, в юридической сфере мы наблюдаем три уровня языка: первый уровень — язык права, второй язык юридической практики, третий — язык юридической науки. В одних случаях язык науки выступает как метаязык, в других - как язык третьего уровня» [Черданцев 2012: 21]. Учитывая такую постановку вопроса, термин «превентивное правосудие» следует отнести к метаязыку.

В исследовании будем опираться на методологию появившейся в России во второй половине XX века науки о терминах - терминоведения, которая является самостоятельной комплексной дисциплиной, использующей, главным образом, методологию лингвистики.

Научное терминотворчество является необходимым условием научного познания. В результате научной деятельности возникают искусственные языковые единицы - термины. Многогранность такого явления, как термин, 
обусловила отсутствие единой исчерпывающей дефиниции и длящиеся по этому поводу споры. Мы будем пользоваться в своем исследовании самой распространенной дефиницией данного явления (на сегодня насчитывается около 190 определений), которая наиболее кратко, но при этом емко отражает данное понятие - термин как «особая языковая единица, основное средство выражения научного понятия» [Багана 2016: 9]. Также интересны будут развернутые определения авторов с различными мнениями на эту тему, которые с разных сторон иллюстрируют свойства термина, но одновременно позволяют прийти к общему знаменателю.

«Научный термин - это языковая единица (слово или словосочетание) преимущественно субстантивного характера, конвенционально соотносящаяся с понятием и предметом профессиональной сферы и служащая для концентрации, фиксирования, хранения и передачи профессиональной информации» [Лемов 2000: 76]. Самое ценное для нас в этом определении - это представление о термине как об особой языковой единице. Языковые единицы, «в отличие от фонем, обладают определенным закрепленным за ними значением. К таким единицам относятся слово, словосочетание, фразеологическая единица» [Ахманова 2010: 146].

«Принадлежность терминологической единицы к знаковой системе языка подтверждается тем, что термин может быть словом или словосочетанием и обладать такими семантическими и формальными признаками единиц языка, как денотативное, сигнификативное, синтагматическое, категориальное и грамматическое значения» [Багана 2016: 9]. Также в отечественном терминоведении существует представление о термине как о специфическом знаке языковой системы. Так, например, Ф. А. Циткина считает, что «термин - это языковой знак, репрезентирующий научное понятие специальной, профессиональной отрасли знания» [Циткина 1988: 10]. Важным в понимании языкового знака является единство понятия и акустического образа, под которым понимается психический отпечаток звучания в мозгу человека. То есть словосочетание «превентивное 
правосудие», являясь языковым знаком, только в таком звуковом воплощении может соответствовать психическому явлению, которое оно озвучивает.

Так как в терминологических исследованиях используется системный подход, то следует учитывать уровень языка. «Один из основных аспектов (ярусов) языка - фонетика, морфология, синтаксис, лингвостилистика мыслимых как ступень в иерархии подсистем языка» [Ахманова 2010: 488]. При членении единицы определенного уровня происходит переход на уровень ниже, в своем уровне единица целостна, неделима. Также термин исследуется во взаимосвязи с терминосистемой (организованной совокупностью терминов в специальном языке определенной области знания), элементом которой он является. Терминосистема в терминоведческом исследовании приравнивается к контексту. «При таком рассмотрении термина возникает положение о его относительности. Будучи лексемой, термин не обладает постоянными семантическими и формальными свойствами, а приобретает эти свойства временно, пока он находится в рамках определенной терминосистемы» [Багана 2016: 29].

Под лексемой понимается любая составная единица семантического уровня, семантическое содержание которой нельзя вывести ни из ее синтаксического построения, ни из семантики составляющих ее элементов, это лексическая морфема [Ахманова 2010: 214]. Морфема в свою очередь определяется как «наименьшая (предельная неделимая далее без потери данного качества) и регулярно воспроизводимая согласно моделям данного языка единица системы выражения, непосредственно соотносимая с соответствующим ей элементом системы содержания (семемой)» [Ахманова 2010: 240]. Это значит, что термин следует относить к высшим уровням языка, конкретно лексическому уровню, а элементы термина при разложении переходят на уровень ниже, следовательно, теряют свое значение (семантическое содержание). Следует, впрочем, заметить, что обе составляющие термина «превентивное правосудие» являются 
самостоятельными терминами, но относятся уже не к третьему уровню (языку науки), а ко второму уровню (языку юридической практики), но одновременно все еще метаязыку.

Второе определение лексемы говорит нам о том, что на лексическом уровне (это уровень совокупности лексем) термин является предельной неделимой единицей уровня. То есть все логические операции по разложению термина и анализу его составных частей приводят к переходу на более низкий уровень языка и потере термином его свойств и являются по сути результатом непонимания единства формы и содержания.

Таким образом, несмотря на различные подходы ученых, в целом можно выделить общее в их понимании, это единство и неделимость термина, так как в рамках своей отрасли он является как бы атомом (единицей, знаком) этого знания и в концентрированном виде хранит в себе большой пласт накопленных знаний. Термин исследуется традиционными методами исследования, в нашем случае, словосочетаний. Следует подчеркнуть, что за единицу рассмотрения следует принимать термин в совокупности с его определением.

Чтобы обосновать свою позицию по отношению к понятию «превентивное правосудие» как к термину, а следовательно, к его смысловой целостности, мы проверим, соблюдены ли все требования, предъявляемые к термину, либо же исследуемое выражение является противопоставляемым терминам свободным словосочетанием. Стоит подчеркнуть, что речь идет об узкоспециальном научном термине, ведь данное выражение применяется сугубо в рамках исследований нотариата, то есть он характерен для конкретной профессии (нотариуса) в рамках определенной отрасли науки (юриспруденции как отрасли знания).

Для того чтобы отделить термины от других слов, следует проверить наличие основных требований, предъявляемых к научно-техническому термину, сформулированных Д. С. Лотте. 
Итак, идеальный (именно идеальный, ведь последние исследования привели терминоведов к пониманию требований, предъявляемых к термину, как основных желательных свойств, которыми он должен обладать) научнотехнический термин должен, по Д. С. Лотте, быть однозначным, точным, системным, кратким, не должен иметь синонимов.

Однозначность (моносемантичность) - это соответствие одному научному термину только одного понятия в рамках одной терминосистемы. Выше мы уже приводили авторскую трактовку выражения «превентивное правосудие», то есть как термин оно профессионально дефинировано. Другие значения, даже если выйти за рамки данной терминосистемы, которую можно было бы широко определить как юридическую, нам неизвестны. Следовательно, данный критерий соблюден.

Второй критерий отграничения термина от нетермина - точность. Не вдаваясь в пространные рассуждения о том, может ли вообще иметь место точность в гуманитарных науках, к коим юриспруденция относится, поясним, что данный критерий связан с анализом соотношения триады «объект - понятие - имя». Несмотря на то, что данные требования разрабатывались для научно-технических терминов, критерий точности можно применить и к абстрактному понятию. На наш взгляд, имя «превентивное правосудие» достаточно точно выражает представление об идеальном объекте, то есть нотариате, хотя все это является абстракцией, и даже в некотором роде фикцией, так как не существует независимо от человека, а живет только в его представлении. Понятие (дефиниция) как бы соединяет объект с его именем, конкретизирует его, рассматривает с разных сторон. Здесь и соотнесение нотариата с судебными органами (правосудии в его прямом, принятом в юриспруденции значении), и акцентирование внимания на общей направленности нотариальной деятельности на охрану права и предупреждение нарушений закона. Точность данного термина заключается в монолитности триады и способности термина максимально точно отразить в нем сущностные представления о явлении (объекте). Эта 
точность очевидно субъективна, но хорошо отражает авторскую точку зрения на объект изучения, акцентирует внимание на определенной подчеркнутой автором характеристике исследуемого объекта (справедливости для всех обратившихся до того, как чье-то право будет нарушено и для того, чтобы оно нарушено не было).

Третий критерий отграничения термина от нетермина - системность (согласование с другими имеющимися в терминосистеме терминами, по Д. С. Лотте). Термин «превентивное правосудие» сегодня согласован с такими терминами, как небюджетный нотариат (нотариат латинского типа), нотариат вообще и нотариальная деятельность, нотариальная охрана права, нотариальная защита права. В данной терминосистеме термин существует уже 18 лет и за это время, благодаря поддержке многих исследователей нотариата [Тарбагаева 2006: 10], вошел в доктрину и стал объектом исследований. Но перехода из уровня метаязыка юридической доктрины не произошло, и возможно никогда не произойдет, подобно тому, как это не произошло с такими выражениями, как «правовая ткань», «правовое поле», «правовая материя» [Алексеев 1995: 14].

Системность разными авторами понимается по-разному, некоторые даже придерживаются мнения, что системность, наряду с мотивированностью, является неотъемлемым свойством термина вообще, так как термин существует внутри терминосистемы и внутри языка вообще, следовательно, несистемным быть не может. Под системностью можно понимать как системность словообразования (по А. А. Реформатскому), так и соотнесенность с той или иной терминологической системой (Б. Н. Головин, Р. Ю. Кобрин, А. В. Суперанская и др.).

«Словообразовательные средства в терминологии представляют собой определенную систему. Каковы же, по мнению исследователей, особенности словообразования в терминологии? В терминообразовании активны и продуктивны такие способы создания наименований, как семантический, синтаксический и морфологический» [Литвиненко 2007: 143]. Когда речь 
идет об образовании термина-слова, то речь идет о лексической номинации.

Словарь О. С. Ахмановой определяет номинацию как назывную функцию или сторону слова, семантический аспект слова как употребляемого (возникающего) в данной речевой ситуации или контексте. Под синтагмой О. С. Ахманова понимает двухчленную структуру, члены которой соотносятся как определяемый (T) и определяющий (T1), причем этими членами могут быть как слова, так и морфемы [Ахманова 2010: 270], а термины-словосочетания образуются путем синтагматической номинации (называние посредством словосочетаний). В таком случае способ, которым образован термин превентивное правосудие, - это синтаксическая деривация.

В терминологии синтаксическим способом создаются многочисленные составные термины, или термины-словосочетания, а сам этот способ является одним из основных, обладающих высокой степенью продуктивности.

Термины-словосочетания, выражающие единые целостные понятия, обладают разной степенью смысловой разложимости. Они более устойчивы, по сравнению со свободными словосочетаниями общелитературного языка, по своей лексико-семантической организации. Их можно отнести к числу лексических словосочетаний, характерной особенностью которых является то, что место одного из компонентов заполняется не любым словом соответствующей категории, а лишь некоторыми, образующими определенную семантическую группу.

Этот способ образования терминов является очень продуктивным, так как позволяет детально представить понятие, а также отразить различные видовые характеристики этого понятия. Адъективно-субстантивная модель $\mathrm{A}+\mathrm{S}$. Формула такая: к термину-названию $(\mathrm{S})$, в нашем случае «правосудие», выраженному именем существительным, добавляется определение (А), сужающее значение термина - «превентивное». Определитель выражен прилагательным. Обычно базисное слово выражает родовое понятие, а 
зависимое - видовое, то есть родовое понятие конкретизируется через видовое понятие.

В целом данная модель терминообразования $(\mathrm{A}+\mathrm{S})$ является распространенной для юриспруденции, подобным образом, например, образованы такие термины, как «ювенальная юстиция», большинство терминов, включающих номинацию «право» - «уголовное право», «гражданское право» и т. д. Следовательно, критерий системности соблюден применительно к данному термину.

Четвертый критерий отграничения термина от нетермина - краткость. Термин «превентивное правосудие» можно определить как двухкомпонентное терминологическое словосочетание, оно относительно кратко, разве что в сравнении с многокомпонентными. Данный недостаток компенсируется его благозвучностью, которая сглаживает многосложность каждого из элементов данного словосочетания и двухкомпонентность термина. А тот факт, что этот термин вошел в употребление и нашел единомышленников, которые стали развивать концепцию нотариата как превентивного правосудия, изучать его в разных аспектах, говорит в его пользу и свидетельствует о наличии такого факультативного требования к термину, как устойчивость, то есть воспроизводимость в речи.

Отсутствие синонимов - последний из критериев в данном списке. Думаем, что у термина, подлежащего проверке, нет синонимов. На это могут возникнуть возражения, так как имеется такой вариант, как «предупредительное правосудие», который употребляется параллельно. Думаем, что здесь речь идет не о синониме, а о вариантах и вопросе о предпочтительной форме, использующей средства родного языка. В начале своей статьи В. М. Жуйков предлагает варианты оформления термина: «Какое содержание мы вкладываем в понимание нотариата как института превентивного, предупредительного правосудия?» [Жуйков 1998: 13], он как бы оставляет выбор предпочтительной формы «превентивное / предупредительное» на суд исследователей нотариата, 
выражая их равнозначность. Языку свойственны совершенно объективные законы, например, слова родного языка являются предпочтительными по отношению к заимствованиям. Таким образом, термин должен был бы войти в употребление в варианте с прилагательным из родного языка, но тому могли помешать объективные причины, связанные с конкретной рассматриваемой терминосистемой, а именно с сознанием юристов, которые мыслят элементами этой терминосистемы. Для юристов, которые часто имеют дело с прилагательным «превентивный» в других словосочетаниях, например, «превентивный арест», «превентивное задержание», «превентивные меры», «превенция», также превратившихся в термины, вполне комфортно употребление именно заимствования, которое стало для юристов обыденным. Слово «превентивный» происходит из французского языка, в который, в свою очередь, пришло из латыни. Термины часто имеют иностранное происхождение в силу международного характера науки. Конкретно для юриспруденции исторически особую роль играл латинский язык. Таким образом, язык оказался опосредованным мышлением, и в употребление наравне со словом из родного языка вошло и заимствование.

Данный термин также соответствует и другим критериям, предъявляемым к термину, но не входящим в стандартный набор:

- мотивированность (семантическая прозрачность, свойство его формы давать представление о так называемом терминологическом понятии);

- стилистическая нейтральность (отсутствие экспрессии, эмоциональной выраженности, термин нельзя отнести к определенному стилю)

- наличие научной дефиниции, благозвучность, внедренность [Багана 2016: 35].

Стоит заметить, что в последнее время все больше терминоведов склоняются к мнению, что идеал термина недостижим, и требования к термину являются лишь его желательными свойствами. Число требований, устанавливаемых авторами, различают от 4 до 13. 
Все термины являются особыми знаковыми единицами языка, которые, как известно, неделимы на данном уровне языка. «Превентивное правосудие», как доказано выше, - термин. Следовательно, «превентивное правосудие» это неделимое единство смысла и формы, так как при сложении двух слов на данном языковом уровне мы получаем не сумму смыслов этих слов, но новый смысл, который теряется при расчленении этого единства. Рассматривать термин «превентивное правосудие» следует в рамках того значения, которое в него заложил творец, пополняя метаязык юриспруденции.

Если же исследовать данное словосочетание, не учитывая, что оно является термином, проанализировать его лингвистическими методами, то можно прийти к выводу о его отнесенности к еще более высокому уровню языка. Например, если допустить, что однажды данный термин перекочует из сознания ученых в естественный язык, то данное словосочетание окажется на самом высоком языковом уровне - лигвостилистическом. Если исследовать данный термин с этой точки зрения, то скорее всего, речь идет о частном случае оксюморона, а именно contradictio in adjecto (лат.) - противоречие в определении. Например, кругльій квадрат. Эта семантическая фигура речи, несмотря на определенное противоречие, создает особое образное представление. Несмотря на то, что данный термин существует пока только в узкой научной среде, тем не менее, многие ученые отмечают его образность, и даже некую красоту.

Таким образом, на наш взгляд, понимание данного термина как особой знаковой единицы языка снимает противоречие, вызывающее дискуссии по поводу применимости данного термина к институту нотариата.

\section{ЛИТЕРАТУРА}

1. Алексеев С. С. Теория права. М.,1995.

2. Ахманова О. С. Словарь лингвистических терминов. М., 2010.

3. Багана Ж. Терминообразование в языке науки. М., 2016.

4. Жуйков В. М. Нотариат как институт превентивного правосудия: общие цели, принципы и полномочия. Российская юстиция. 1998. № 6. 
5. Лемов A. B. Система, структура и функционирование научного термина: автореферат дис. ... д-ра филол. наук. Н. Новгород, 2000.

6. Литвиненко Г.И. Способы словообразования как фактор системности в терминологии. Вісник СумДУ. 2007. № 1.

7. Нотариальное право России. Учебник для студентов юридических вузов и факультетов. М., 2003.

8. Тарбагаева Е. Б. Организация и деятельность нотариата в Российской Федерации. СПб., 2006.

9. Циткина Ф. А. Терминология и перевод (к основам сопоставительного терминоведения). Львов, 1988.

10. Черданцев А. Ф. Логико-языковые феномены в юриспруденции. М., 2012.

11. Энциклопедический юридический словарь / Под общ. ред. В. Е. Крутских и В. Н. Додонова. М., 1998.

\section{REFERENCES}

1. Sergeev S. S. Theory of law [Teoriya prava ]. Moscow, 1995.

2. Achmanova O.S. Dictionary of linguistic terms [Slovar' lingvisticheskikh terminov]. Moscow, 2010.

3. Bagana $\mathrm{G}$. The term formation in the language of science [Terminoobrazovaniye $\mathrm{v}$ yazyke naukie]. Moscow, 2016.

4. Zhuykov V. M. The Notarial profession as an institution of preventive justice: General objectives, principles and powers [Notariat kak institut doventiya: obshchiye tseli, printsipy i polnomochiya]. Rossiyskaya iustitsia - Russian justice. Moscow, 1998. Vol. 6.

5. Lemov A. W. System, structure and functioning of the scientific term [Sistema, struktura $i$ funktsionirovaniye nauchnogo termin: Dis. ... kand. filol. nauk]. Nizhny Novgorod, 2000.

6. Litvinenko G. I. Ways of word formation as a factor of system in terminology [Sposoby slovoobrazovaniya kak faktor sistemnosti v terminologii]. Bulletin of SSU.Kiev, 2007. Vol. 1.

7. Notarial law of Russia. Moscow, 2003.

8. Tarbagaeva E. B. The organization and operation of notaries in the Russian Federation [Organizatsiya i deyatel'nost' notariata v Rossiyskoy Federatsii]. St. Petersburg, 2006.

9. Tsitkina F. A. Terminology and translation [Terminologiya i perevod]. Lvov, 1988.

10. Cherdantsev A. F Logical and linguistic phenomena in the law [Logiko-yazykovyye fenomeny v yurisprudentsii]. Moscow, 2012.

11. Encyclopedic dictionary of law. [Entsiklopedicheskiy yuridicheskiy slovar'] Moscow, 1998. 